\title{
Direct current (DC) resistivity and Induced Polarization (IP) monitoring of active layer dynamics at high temporal resolution
}

Doetsch, J.; Fiandaca, G.; Ingeman-Nielsen, Thomas; Christiansen, A.V.; Auken, E.; Elberling, B.

Published in:

Proceedings of Near Surface Geoscience 2015

Publication date:

2015

Document Version

Peer reviewed version

Link back to DTU Orbit

Citation (APA):

Doetsch, J., Fiandaca, G., Ingeman-Nielsen, T., Christiansen, A. V., Auken, E., \& Elberling, B. (2015). Direct current (DC) resistivity and Induced Polarization (IP) monitoring of active layer dynamics at high temporal resolution. In Proceedings of Near Surface Geoscience 2015 (pp. 5)

\section{General rights}

Copyright and moral rights for the publications made accessible in the public portal are retained by the authors and/or other copyright owners and it is a condition of accessing publications that users recognise and abide by the legal requirements associated with these rights.

- Users may download and print one copy of any publication from the public portal for the purpose of private study or research.

- You may not further distribute the material or use it for any profit-making activity or commercial gain

- You may freely distribute the URL identifying the publication in the public portal 


\section{Introduction}

The active layer covering the permafrost thaws every year and has increased in thickness over large tracts of the Arctic (Mishra and Riley, 2014) due to climate change. Freeze-thaw dynamics within the active layer and top permafrost are closely linked to the availability of water and salt in the ground, which influence the freezing point depression and ions (nutrient) translocation in the profile. Geophysical measurements can image permafrost and the active layer at a scale of tens to hundreds of meters. For example, Hubbard et al. (2013) combine LiDAR and geophysical datasets in a cluster analysis to detect zones with different geomorphic, hydrological, thermal and geochemical properties. Time-lapse inversion of repeated direct current (DC) measurements allows both active layer dynamics and interannual permafrost conditions to be delineated vertically as well as laterally, where especially the lateral variations are difficult to obtain from drillings alone. Hauck (2002) introduced DC resistivity for monitoring of alpine permafrost and showed that variations in electrical resistivity can be used to determine the freezing depth. Analyses of a comprehensive DC resistivity monitoring data set from a 7-year study at Schilthorn, Swiss Alps (Hilbich et al., 2008, 2011) have proven the applicability of DC for monitoring of freezing and thawing processes on short-term, seasonal, and long-term scales.

Measurements of induced polarization (IP) are sensitive to the grain surface to pore volume ratio and the grain surface charge (Lesmes and Frye, 2001) and can therefore help to image the different processes associated with freezing of sediments. IP monitoring has been used in field studies to image changes in geochemistry associated with bio-stimulation (Williams et al., 2009) and $\mathrm{CO}_{2}$ injection (Doetsch et al., 2015b) in shallow aquifers, but no study related to permafrost is known to us.

The aim of this study is to demonstrate the potential of using DC and IP monitoring to investigate thaw-freeze dynamics at a High Arctic site in Greenland. For this purpose, we perform time-lapse DC and IP measurements of the ground during freezing in fall and winter (2013-2014) and test how combined DC-IP measurements improve the understanding of the processes occurring during freezing of the ground.

\section{Field site and data acquisition}

The study site $\left(\mathrm{N} 69^{\circ} 15^{\prime}, \mathrm{W}^{\circ} 3^{\circ} 30^{\prime}, 30 \mathrm{~m}\right.$ a.s.1.) is located near the Arctic Station on Qeqertarsuaq/Disko Island on the west coast of Greenland (Fig. 1b). Below-freezing conditions typically prevail in the entire active soil layer from late December until May. Our study area (Fig. 1a) is situated in an area, where the bedrock-valley was filled with loose sediments with an unusually high iron content due to the basaltic source rocks.

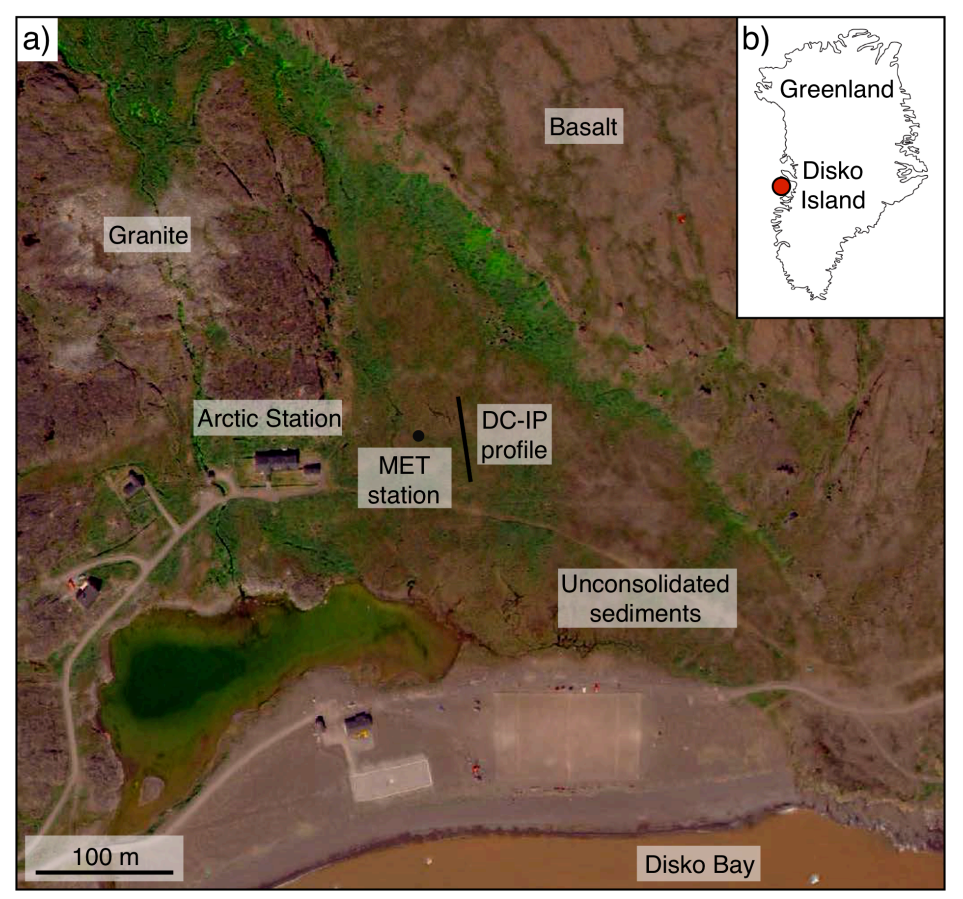

Weather data, including above- and below-ground temperatures, precipitation and soil moisture are continuously recorded at a full water and energy meteorological (MET) station about $100 \mathrm{~m}$ from Arctic Station. The DC-IP profile was installed $30 \mathrm{~m}$ east of the MET station in northsouth direction (Fig. 1a).

Figure 1 General site information with an areal photo of the field site on Disko Island in (a) and its location in western Greenland in (b). 
The DC-IP installation consisted of 64 electrodes installed on a transect with an inline electrode spacing of $0.5 \mathrm{~m}$ for the 42 electrodes in the center and $2 \mathrm{~m}$ towards the ends of the line. Data were colltected using an ABEM Terrameter LS resistivity meter that was connected to a local back storage and to the internet for complete remote control. DC and IP data were collected from July 2013 until February 2014 using Gradient-type electrode configurations. 6-12 complete data sets consiting of 244 configurations were acquired daily. Contact resistances were initially around $2 \mathrm{k} \Omega$, but increased up to $700 \mathrm{k} \Omega$ towards the end of the monitoring period. High-quality DC measurements were acquired during the entire 7-month monitoring period, but IP measurements were compromised after 30 days of freezing, due to the high contact resistances.

\section{DC-IP inversion results}

A total of 1388 DC and 360 DC-IP data sets were inverted using the inversion software AarhusInv (Fiandaca et al., 2012, 2013; Auken et al., 2014). We first inverted the data set of day 0 (Oct. 22, 2013) that marks the last day before the freezing of the ground begins. For the inversion of all other data sets, the day 0 inversion result (Fig. 2) was used as start and prior model. All inversions converged to the estimated error level (6\%) in 3-6 iterations. Fig. 2 shows the DC inversion result for days 0 and 100. The unfrozen resistivity distribution (Fig. 2, day 0 ) shows low resistivities at the surface $(<400 \Omega \mathrm{m})$, intermediate resistivities of $1000-2000 \Omega \mathrm{m}$ between 0.5 and $2 \mathrm{~m}$ depth and low resistivities $(<200 \mathrm{~m})$ below. Shallow resistivities strongly increase with the freezing of the ground (Fig 2, day 100), in many places by more than a factor of 100 . The resistivity of the shallowest $0.5 \mathrm{~m}$ in unfrozen state shows inhomogeneity (resistivity around $\mathrm{x}=34 \mathrm{~m}$ is higher than elsewhere), due to local variations in material composition and soil moisture.

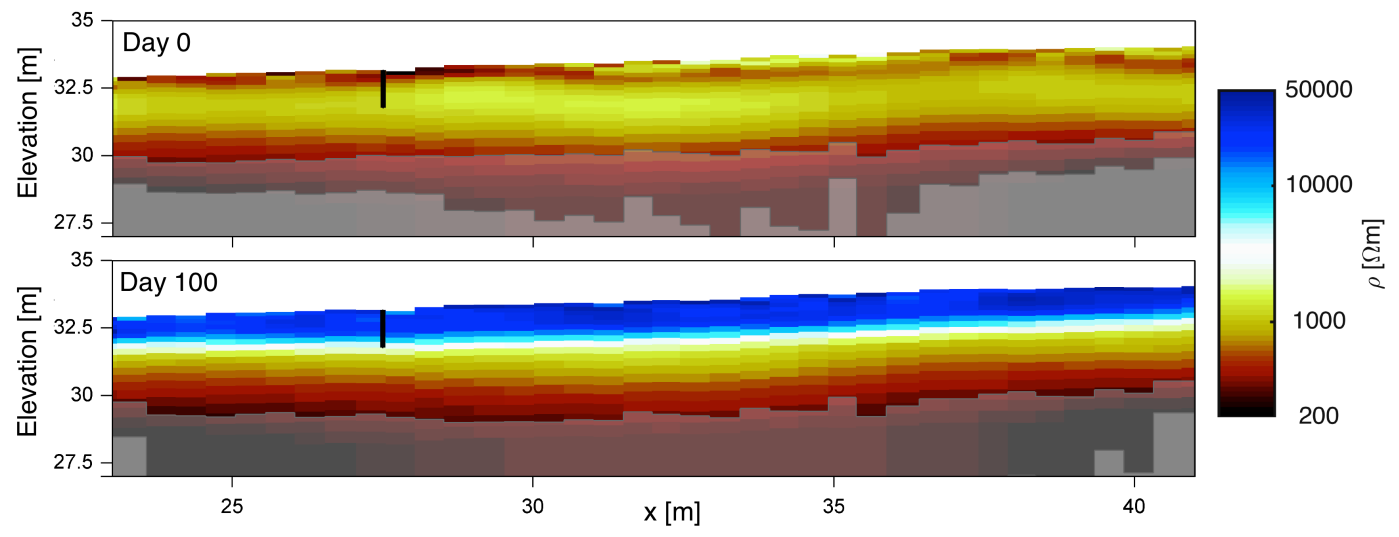

Figure 2 DC inversion result for data collected on Oct 22, 2013 (Day 0), and Jan 30, 2014 (Day 100). Onset of freezing is around day 0. The black line at position $x=27.5 \mathrm{~m}$ marks the borehole with temperature sensors. Shading indicates the depth of investigation with light shading indicating regions that are poorly constrained by the data and fully shaded areas not being constrained at all.

The vertical resistivity profiles at the location of the temperature sensors (marked in Fig. 2) are extracted from all inversion results and are shown in Fig. 3, along with the co-located temperature measurements. With the onset of freezing, temperature decreases and resistivity increases from the surface downwards. For the first 30 days of freezing, temperatures stay relatively mild, the freezing horizon fluctuates between 0 and $0.2 \mathrm{~m}$ depth, and resistivities decrease only in the top layer. Starting from day 30, temperatures decrease significantly, steadily pushing the freezing horizon down (Fig. 3a). This decrease in temperature causes the resistivity to increase strongly from the surface downwards. While there is a clear correlation between the development of temperature and resistivity in Fig. 3, it is not possible to define a single resistivity that defines the transition from unfrozen to frozen ground. 
The combined time-lapse DC-IP inversions (not shown) image a strong decrease of normalized chargeability. The change in normalized chargeability varies along the profile, with changes only effecting the topmost $0.5 \mathrm{~m}$ in some place, while extending to $\sim 1.5 \mathrm{~m}$ in others. For details of the DCIP inversions, please see Doetsch et al. (2015a).
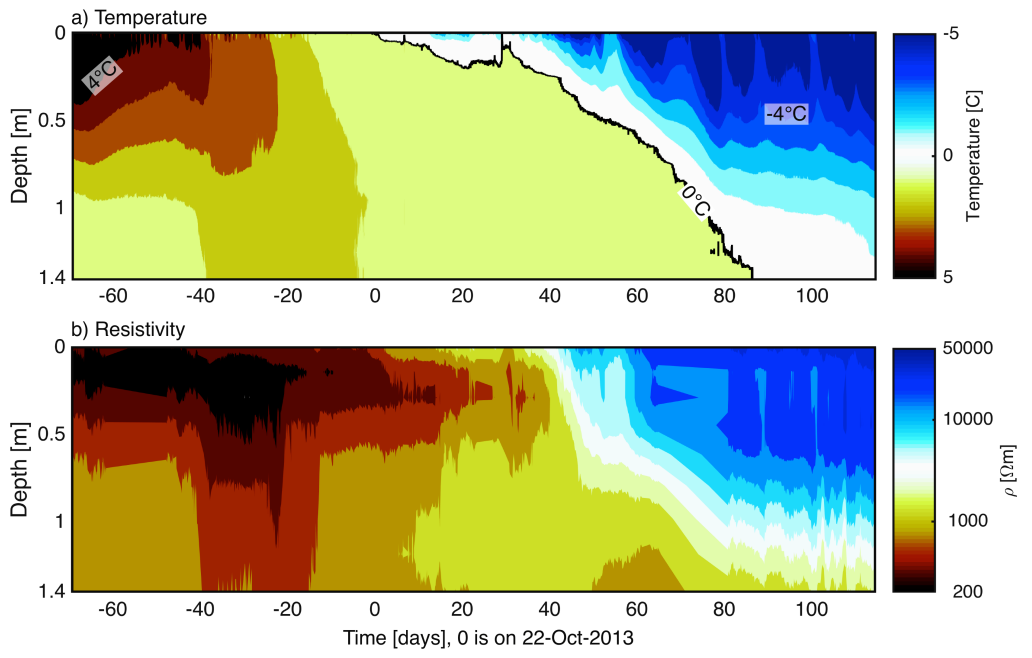

Figure 3 Plots of (a) temperature and (b) resistivity at the borehole on the DC-IP profile as a function of time and depth. The black line in the temperature plot indicates the freezing $\left(0^{\circ} \mathrm{C}\right)$ depth. Resistivity and temperature show a clear correlation, but it is not possible to directly translate resistivity into temperature.

\section{Discussion and interpretation}

The resistivity of unfrozen and frozen soil depends on lithology (rock type), porosity and soil moisture. Direct translation between resistivity and (below freezing) temperature is therefore not possible, as illustrated by Fig. 3. Plotting resistivity against temperature in a scatter plot can reveal a relationship between the two parameters. Fig. 4 shows that there is a strong increase of resistivity around $0^{\circ} \mathrm{C}$, followed by an increase that is consistent with an exponential relationship between resistivity and temperature (linear relationship between the logarithm of resistivity and temperature). This is the behavior predicted for saturated sand and gravel by Hoekstra et al. (1975) and confirmed by others (e.g., Hauck, 2002). The immediate increase of resistivity around $0^{\circ} \mathrm{C}$ shows that ion concentration in the pore water is small and that many large pores exist. In these pores, water can freeze rapidly at $0^{\circ} \mathrm{C}$, until the ion concentration in the remaining unfrozen water increases, depresses the freezing point and builds the interfacial layer. After the initial strong increase in resistivity at $0^{\circ} \mathrm{C}$, the further increase approximately follows an exponential relationship between resistivity and temperature.

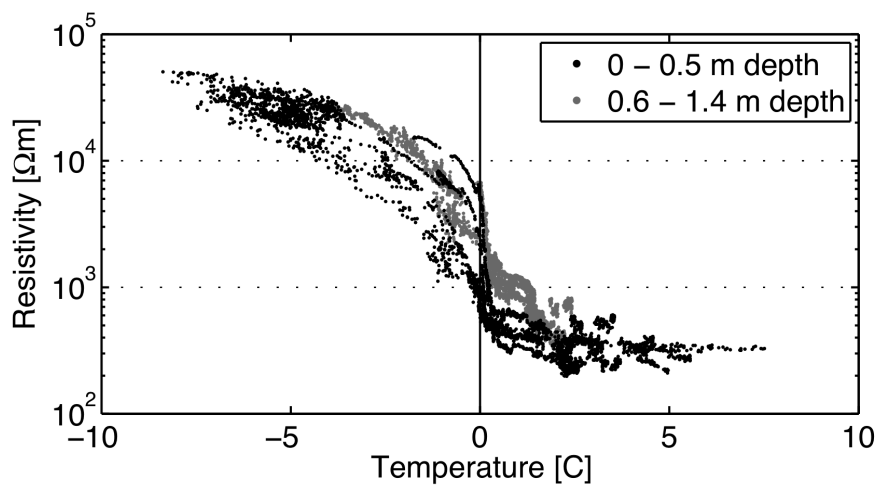

Figure 4 shows a scatter plot of resistivity and temperature that illustrates the strong increase of resistivity at $0{ }^{\circ} \mathrm{C}$ and a further increase with decreasing temperature. 


\section{Conclusions and Outlook}

Seven months of DC-IP data were recorded for active layer monitoring in western Greenland. Our results show that time-lapse DC-IP measurements and inversion can be used to non-intrusively monitor the active layer freezing processes at a scale of tens to hundreds of meters. Future investigations could include larger 3D setups to resolve spatial variability, as well as calibration with laboratory measurements and coupling of the DC-IP inversions with simulators for heat conduction and flow and transport in freezing soils. DC-IP monitoring could play a major role in understanding these freezing processes and monitor the state of the active layer on a relevant space and time scale.

\section{Acknowledgements}

The authors would like to thank Simon Ejlertsen, Charlotte Sigsgaard and the Arctic Station for their support. Funding for this study was provided by the Danish National Research Foundation (CENPERM DNRF100) and the HydroGeophysics Group at Aarhus University.

\section{References}

Auken, E. et al. [2014] An overview of a highly versatile forward and stable inverse algorithm for airborne, ground-based and borehole electromagnetic and electric data, Explor. Geophys., doi:10.1071/EG13097

Doetsch, J., T. Ingeman-Nielsen, A. V. Christiansen, G. Fiandaca, E. Auken, and B. Elberling [2015a] Direct current (DC) resistivity and Induced Polarization (IP) monitoring of active layer dynamics at high temporal resolution, Cold Regions Science and Technology, under review.

Doetsch, J., G. Fiandaca, E. Auken, A. Christiansen, A. Cahill, and R. Jakobsen [2015b] Field-scale timedomain spectral induced polarization monitoring of geochemical changes induced by injected $\mathrm{CO} 2$ in a shallow aquifer, Geophysics, WA113-WA126, doi:10.1190/geo2014-0315.1.

Fiandaca, G., E. Auken, A. V. Christiansen, and A. Gazoty [2012] Time-domain-induced polarization: Full-decay forward modeling and 1D laterally constrained inversion of Cole-Cole parameters, Geophysics, 77(3), E213-E225, doi:10.1190/geo2011-0217.1.

Fiandaca, G., J. Ramm, A. Binley, A. Gazoty, A. V. Christiansen, and E. Auken [2013] Resolving spectral information from time domain induced polarization data through 2-D inversion, Geophys. J. Int., 192(2), 631-646, doi:10.1093/gji/ggs060.

Hauck, C. [2002] Frozen ground monitoring using DC resistivity tomography, Geophys. Res. Lett., 29(21), 2016, doi:10.1029/2002GL014995.

Hilbich, C., C. Hauck, M. Hoelzle, M. Scherler, L. Schudel, I. Völksch, D. Vonder Mühll, and R. Mäusbacher [2008] Monitoring mountain permafrost evolution using electrical resistivity tomography: A 7-year study of seasonal, annual, and long-term variations at Schilthorn, Swiss Alps, J. Geophys. Res., 113(F1), F01S90, doi:10.1029/2007JF000799.

Hilbich, C., C. Fuss, and C. Hauck [2011] Automated Time-lapse ERT for Improved Process Analysis and Monitoring of Frozen Ground, Permafrost and Periglac. Process., 22(4), 306-319, doi:10.1002/ppp.732.

Hoekstra, P., P. Sellmann, and A. Delaney [1975] Ground and airborne resistivity surveys of permafrost near fairbanks, alaska, Geophysics, 40(4), 641-656, doi:10.1190/1.1440555.

Hubbard, S. S. et al. [2013] Quantifying and relating land-surface and subsurface variability in permafrost environments using LiDAR and surface geophysical datasets, Hydrogeol J, 21(1), 149-169, doi:10.1007/s10040-012-0939-y.

Lesmes, D. P., and K. M. Frye [2001] Influence of pore fluid chemistry on the complex conductivity and induced polarization responses of Berea sandstone, J. Geophys. Res., 106(B3), 4079-4090.

Mishra, U., and W. J. Riley [2014] Active-Layer Thickness across Alaska: Comparing Observation-Based Estimates with CMIP5 Earth System Model Predictions, Soil Science Society of America Journal, doi:10.2136/sssaj2013.11.0484.

Williams, K. H., A. Kemna, M. J. Wilkins, J. Druhan, E. Arntzen, A. L. N'Guessan, P. E. Long, S. S. Hubbard, and J. F. Banfield [2009] Geophysical Monitoring of Coupled Microbial and Geochemical Processes During Stimulated Subsurface Bioremediation, Environ. Sci. Technol., 43(17), 6717-6723, doi:10.1021/es900855j. 